variable selon les ethnies puisqu'elle atteindrait $10 \%$ chez les Esquimaux. Sous forme d'un précurseur de taille supérieure à 200000 daltons, l'enzyme voyage à travers le réticulum endoplasmique, puis l'appareil de Golgi, où elle se glycosyle pour aboutir à la surface des microvilli intestinaux, où des protéases la scindent en sucrase et isomaltase. Les sujets déficients ne peuvent utiliser le saccharose et l'isomaltose et leur capacité d'utiliser le maltose est franchement diminuée.

Les travaux antérieurs portant sur la muqueuse intestinale totale concluaient tantôt à la présence, tantôt à l'absence de protéine immunoréactive. Des auteurs suisses [I] ont eu l'idée de combiner la technique des anticorps monoclonaux et la microscopie électronique. Ils ont ainsi pu localiser la protéine dans la membrane microvillaire chez les sujets normaux, alors que chez le malade la quasi-totalité était restée dans l'appareil de Golgi. D'autres techniques ont montré que la quantité de protéine immunoréactive était du même ordre que chez les témoins et qu'il s'agissait du précurseur apparemment normalement glycosylé. Le précurseur avait donc été synthétisé, avait traversé sans encombre le réticulum endoplasmique mais n'avait pu franchir l'ultime étape pour atteindre la surface de la cellule. La présence dans la muqueuse intestinale d'une activité normale de lactase prouvait que l'ensemble de l'appareil de Golgi n'était pas en cause. Cette "panne " spécifique d'une enzyme en route vers sa destination normale n'a pas encore refu d'explication satisfaisante.

J.-C. D.

I. Hauri HP, Roth J, Srechi EE, Lentze MJ. Transport to cell surface of intestinal sucraseisomaltase is blocked in the Golgi apparatus in a patient with congenital sucrase-isomaltase deficiency. Proc Natl Acad Sci USA 85; 82, 4423-7.

$\mathrm{m} / \mathrm{s} \mathrm{n}^{\circ}>$ novembre 85

\section{Les souris transgéniques au secours des immunologistes cellulaires}

a technologie des animaux transgéniques, les souris avant tout, sera détaillée dans un prochain numéro de médecine/sciences. En bref, il s'agit de microinjecter un gène cloné dans un pronucleus d'œuf fécondé, de réimplanter cet œuf dans l'animal conditionné et, après la naissance des embryons, de détecter ceux des animaux nouveau-nés qui ont intégré le gène injecté. Cet ADN exogène intégré se transmet comme un caractère héréditaire mendélien; exprimé de manière correcte, il confère alors un nouveau caractère héréditaire à la descendance de l'animal transgénique.

De récents succès viennent d'être obtenus par cette méthode avec des gènes codant pour les antigènes de classe I et II du complexe majeur d'histocompatibilité (CMH). Frels et al [1] ont ainsi introduit un gène porcin de classe I du CMH dans une souris dont toutes les cellules se sont avérées positives pour l'expression de l'antigène porcin. Une greffe de peau de l'animal transgénique à une souris normale de la souche parentale est rapidement rejetée, preuve que l'antigène porcin est fonctionnel. Des expériences ultérieures diront en outre si le gène introduit permet aux souris transgéniques d'acquérir une nouvelle spécificité restreinte de leurs lymphocytes $T$ cytotoxiques, qui pourraient ainsi reconnaitre non seulement des cellules exprimant les antigènes de classe I du CMH murin, mais aussi des cellules n'exprimant que l'antigène porcin.

Les antigènes de classe II (antigènes $\mathrm{A}$ et $\mathrm{E}$, chacun constitué de deux types de chaine, $\alpha$ et $\beta$ ) sont reconnus par les cellules $T$ " helper " (auxiliaires) et leur expression est requise pour le développement normal de l'immunité contre certains antigènes. Une souche de souris ayant ainsi une délétion partielle du gène $\mathrm{E}_{\alpha}$ n'exprime pas l'antigène $\mathrm{E}$ à la surface de ses cellules et ne répond pas à l'immunisation par un antigène synthétique tel que le polyglutamyl-lysyl-phénylalanine.

Trois équipes, dont celle de Pierre Gerlinger et de Christophe Benoist dans le laboratoire du Pr Chambon à Strasbourg, viennent de réussir à corriger tous ces défauts par microinjection d'un gène $E_{\alpha}$ normal dans les œufs fécondés de souris de la souche mutante. Les possibilités ainsi ouvertes de modifier chez l'animal l'expression de leurs antigènes d'histocompatibilité, voire de provoquer l'expression d'antigènes "artificiels" obtenus in vitro par fabrication de gènes hybrides, devraient offrir aux immunologistes cellulaires des outils incomparables pour analyser les phénomènes complexes du développement du système immunitaire et des mécanismes de reconnaissance par les cellules lymphocytaires $T$.

A. K.

I. Frels WI, Bluestone JA, Hodes RJ, et al. Expression of a microinjected porcine class I major histocompatibility complex gene in transgenic mice. Science $1985: 228 ; 577-80$.

2. Le Meur M, Gerlinger P, Benoist C, Mathis D. Correcting an immune response deficiency by creating $E_{a}$ gene transgenic mice. Nature 1985: 316; 38-42.

3. Yamanura KI, Kibutani $\mathrm{H}$, Folsom V, et al. Functional expression of a microinjected $\mathrm{E}_{\alpha}$ gene in C 57 BL/6 transgenic mice. Nature 1985: 316; 67-9.

4. Pinkert, et al., cité par Stemmetz M. Immune response restored by gene therapy in mice. Nature 1985: $316 ; 14-5$.

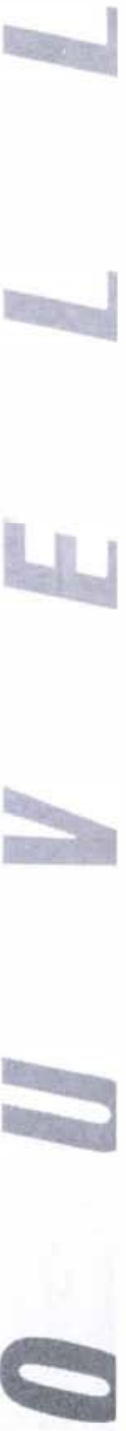

